www.nature.com/jes

\title{
EDITORIAL
}

\section{Close encounters: Reflections on the successes and near misses of exposure science}

Journal of Exposure Science and Environmental Epidemiology (2010) 20, 1; doi:10.1038/jes.2009.65

Nearly every day there is a story in the media that demonstrates how knowledge of exposures empowers individuals to make more informed decisions regarding their health and the health of their families, and how societies and governments can make health-protective decisions. There are celebrated successes such as children's exposures to lead or exposure to tobacco smoke that have resulted in some of the most significant interventions in the history of public health management. And there are legacies such as Superfund sites that remain a challenge, in particular in communities that are economically disadvantaged. The $\mathrm{H} 1 \mathrm{~N} 1$ virus reminds us that health and disease are conditions narrowly separated by exposure - in particular, for those who are susceptible.

Discovery of lead in children's toys, the rush to use recycled construction materials, debates over the safety of nanotechnologies, and the unabashed embrace of green chemistry as the panacea to chemical exposures caution us that lessons from history should not be forgotten. Exposure science can enable sustainable innovation and help avoid the unintended consequences of new materials, applications, and policies. Therefore, this year marks a time for retrospectiontime to revisit and celebrate the successes of exposure science, evaluate lessons learned, and consider how these can inform future decisions.

The International Society of Exposure Science (ISES) and the Journal of Exposure Science and Environmental Epidemiology (JESEE) have partnered on a project marking the 20th anniversary of the formal establishment of ISES. Each JESEE issue in 2010 starting with the second issue will contain one or two exposure science digests articles that showcase successes and that have had a broad impact on understanding exposures, improving public health, advancing risk management, informing other related disciplines, and impacting policy. While these articles will mostly celebrate historical successes, they will also discuss the relevance of these successes to some of the most pressing public health issues we face today. Changes in the field of exposure have never been greater and the pace of change will only accelerate. The final issue of 2010 will highlight future scientific directions that are expected to have a profound impact in the field of exposure science and related disciplines.

This project, dubbed the "Anniversary Project", was designed to increase the impact and future viability of exposure science. It targets public health, regulatory, and legislative decision-makers, many of whom recognize the importance of exposure science but are daunted by its complexity and the lack of understanding about how to incorporate exposure information into their decisions. The Anniversary Project represents efforts by ISES members to promote the vision of creating a safer and healthier world by advancing the science of exposure.

We appreciate all of the outstanding nominations we received for these review topics, and greatly value the engagement and participation of ISES members and the broader exposure science community. We are excited about this endeavor and hope you will enjoy this journey through history and across the bridge to the future of exposure science.

TINA BAHADORI

President, ISES

DANA BOYD BARR Editor-in-Chief 